\title{
A CORRECTION TO "THE BOUNDARY PROBLEM OF AN ORDINARY LINEAR DIFFERENTIAL SYSTEM IN THE COMPLEX DOMAIN"*
}

BY

\author{
RUDOLPH E. LANGER
}

In formula (6.1) replace $x_{*}^{(n, \imath)}$ by $x_{*}^{(h, \nu)}$, and $\Re(\lambda)$ by $\Omega_{\nu}(\lambda)$, and add $\nu=1,2, \cdots, n$. To derive (6.3) (with the accidentally omitted sign of integration from $x_{*}^{(n, l)}$ to $x$ over the respective members of the sum), multiply (6.1) by $\mathfrak{S}(x)$ on the left, by $\mathfrak{S}(\lambda) \Im_{v, \nu} \mathfrak{S}^{-1}(x)$ on the right, and sum as to $\nu$. In this formula and everywhere subsequently replace $\Omega(\lambda) \mathbb{C}(\lambda)$ by $\sum_{v=1}^{n} \Omega_{\nu}(\lambda) \mathbb{E}(\lambda) \Im_{\nu, v}$. The argument given shows that each $\Omega_{\nu}(\lambda)$ is nonsingular. In and just before (6.9) replace $\Omega^{-1}(\lambda)$ by $\sum_{v=1}^{n} \Omega_{\nu}^{-1}(\lambda) \Im_{\nu, v}$. The stated result follows. (Throughout the discussion the hitherto undefined points $x_{*}^{(h ; l)}$ with $h=l$, and the paths from them may be chosen arbitrarily in $X$.)

* Received by the editors October 5, 1939. Cf. these Transactions, vol. 46 (1939), pp. 151-190.

UNIVERSITY OF WISCONSIN, Madison, Wis. 